\title{
Concurrent Lateral Condyle Mass Fracture With Olecranon Fracture: A Case Report and Brief Review of Literature
}

\author{
Munir Farooq, ${ }^{1}$ Younis Kamal, ${ }^{1,}$ Hayat Ahmad Khan, ${ }^{1}$ Naseemul Gani, ${ }^{1}$ Adil Bashir Shah,, Mohammed \\ Ashraf Khan, ${ }^{1}$ and Shahid Bhat ${ }^{1}$ \\ ${ }^{1}$ Postgraduate Department of Orthopaedics, Government Medical College, Jammu and Kashmir, India \\ "Corresponding author: Younis Kamal, Postgraduate Department of Orthopaedics, Government Medical College, Srinagar, Jammu and Kashmir, India. Tel: +91-06966960, Fax \\ +91-1942423389, E-mail: kdryounis@gmail.com
}

Received 2014 October 27; Revised 2015 February 09; Accepted 2015 November 30.

\begin{abstract}
Introduction: There is very limited literature describing the association of lateral condyle mass (LCM) fracture of the distal humerus associated concurrently with olecranon fracture. Herein, a case is reported of a displaced LCM fracture with displaced olecranon fracture, due to complex trauma while getting out of a vehicle, which was managed by open reduction and internal fixation.

Case Presentation: A 4.5- year- old boy suffered severe pain and swelling around his right elbow due to trauma which he suffered while trying to get out of a vehicle which was in motion. Plain radiographs of the anteroposterior, lateral, and oblique views showed a displaced lateral mass fracture associated with a displaced olecranon fracture. Open reduction and internal fixation was carried out and near normal function was achieved.

Conclusions: In view of the paucity of literature and rare incidence of this injury, this case report highlights the need to be aware of other injuries which can occur in association with LCM fractures in children.
\end{abstract}

Keywords: Lateral Mass Fracture, Olecranon Fracture, Complex Elbow Injuries

\section{Introduction}

Fractures involving the lateral condylar region in the immature skeleton either cross the physis or follow it for a short distance into the trochlea. They constitute about $16.9 \%$ of all distal humeral fractures (1). Fractures of the lateral condyle physis are only occasionally associated with other injuries like dislocation of the elbow, radial head fracture, and fractures of the olecranon. There is very little literature describing an association of LCM fracture of the distal humerus associated concurrently with olecranon fracture (2). Undisplaced LCM fractures of the elbow in children can be managed conservatively while displaced fractures require open reduction and internal fixation (3$6)$.

This article presents a case report of a displaced LCM fracture with displaced olecranon fracture due to complex trauma while getting out of a moving vehicle, which has been managed by open reduction and internal fixation.

\section{Case Presentation}

A 4.5- year- old boy suffered severe pain and swelling around his right elbow joint due to trauma he received while he tried to get out of a vehicle in which he was travelling, while the vehicle was still running. Initially, when he opened the rear door of the vehicle, the driver applied the brakes, and suddenly, he suffered direct trauma to his right elbow due to deceleration of the vehicle. He fell on the road on his outstretched hand and suffered direct, as well as indirect (double), trauma in the same event. On presentation to the emergency department, the movements of his elbow joint were painful and limited. A neurovascular examination of his right upper extremity was normal. There was no past history of right elbow joint injury and his past medical history was unremarkable.

Plain radiographs of the elbow joint (anteroposterior, lateral, and oblique views) showed a displaced LCM fracture associated with a displaced olecranon fracture (Figures 1 and 2). After preliminary splintage of the limb, the patient was planned for open reduction and internal fixation.

Under general anaesthesia and via the posterior paratriceptal approach to the elbow joint, the lateral condyle fracture was anatomically reduced under direct vision and fixed with two K-wires laterally. After stabilizing the LCM fracture, the olecranon fracture was reduced by towel clip and fixed with two K-wires. The two fixed fractures were found stable on full range of motion of the elbow joint. The wound was closed back in layers, the wires were embedded under the skin and posterior above, and an elbow splint was applied. The patient was discharged on the splint and followed in the outpatient clinic weekly with check X-rays at 1, 3, and 6 weeks (Figures 3 and 4). The posterior splint 


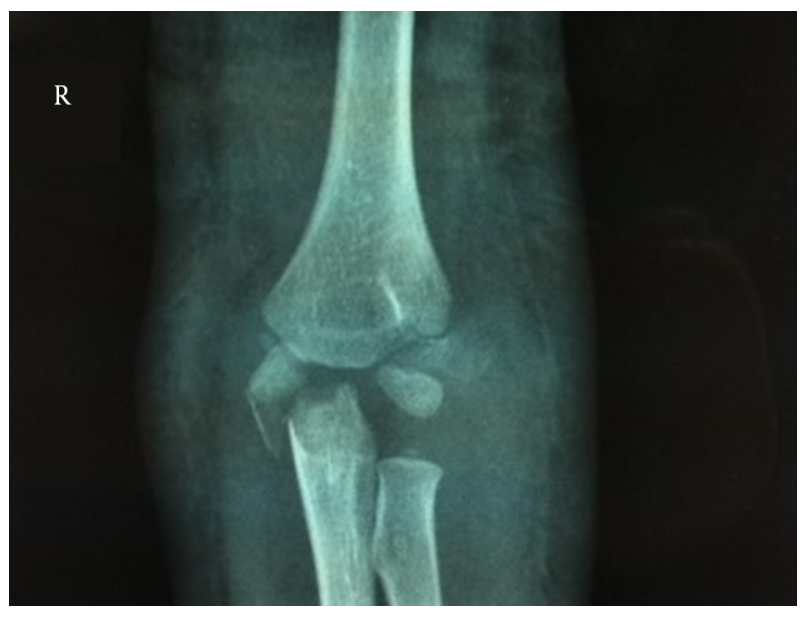

Figure 1. Preoperatvie X Ray AP View

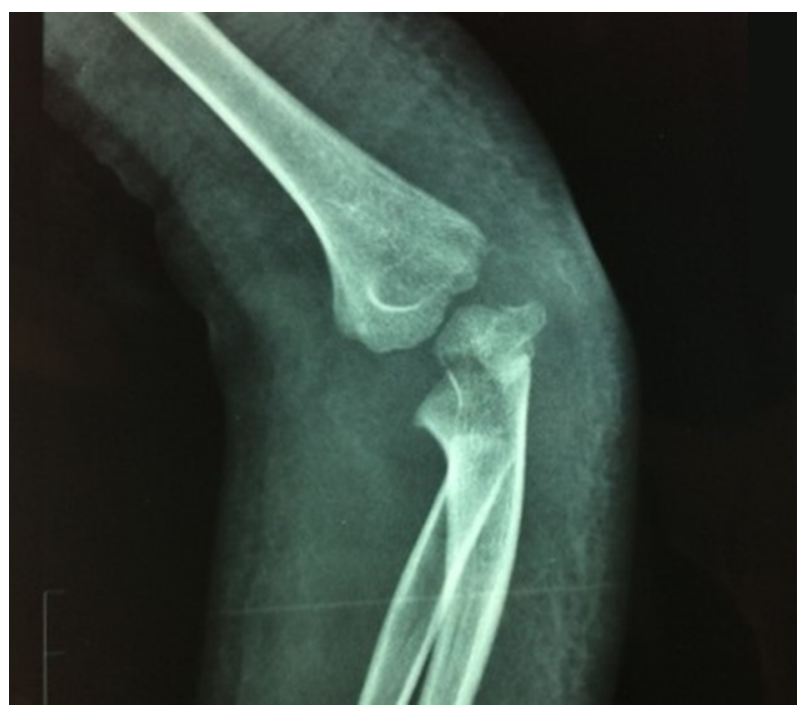

Figure 2. Preoperative X Ray Lateral View

was removed at 6 weeks and the K-wires were removed at 8 weeks on day care basis under intravenous sedation. Range of motion exercises of the elbow joint were started and the patient was followed in the outpatient clinic monthly up to 6 months with follow-up X-rays at 3 months and 6 months. At the 6 month interval, the patient had no pain or instability around the right elbow joint and had nearly full range of motion; flexion 1300 , extension $0^{\circ}$, pronation $70^{\circ}$, supination $80^{\circ}$. The X-rays at 6 months showed bony union of both the lateral condyle and olecranon with no signs of capitular necrosis (Figure 5). The carrying angle of the right upper limb was comparable to the opposite side.
At 12 weeks follow-up, the clinical photos are shown in Figure 6 .

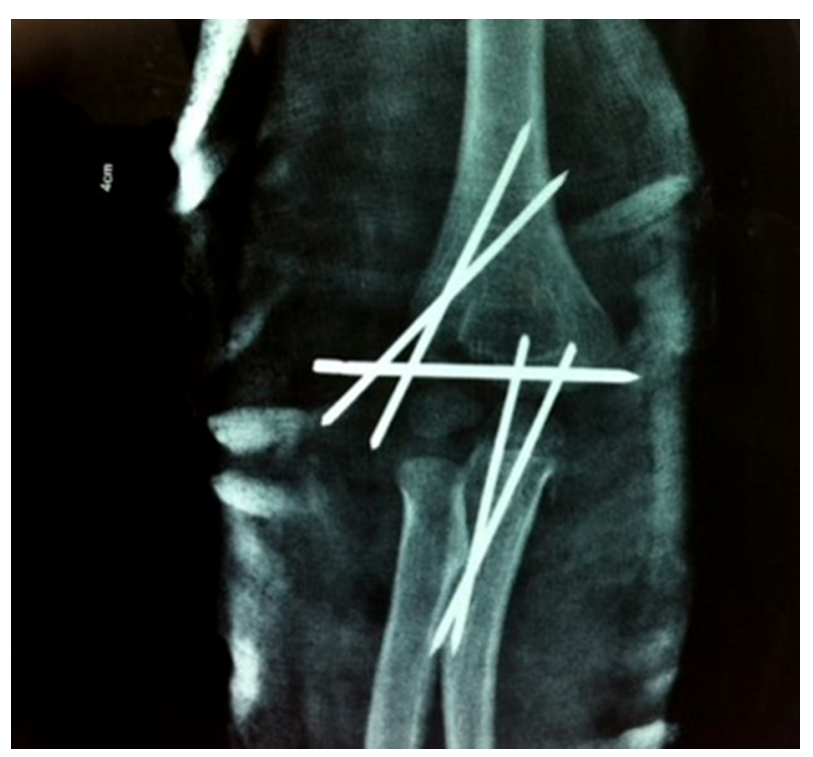

Figure 3. Immediate Postoperative X Ray

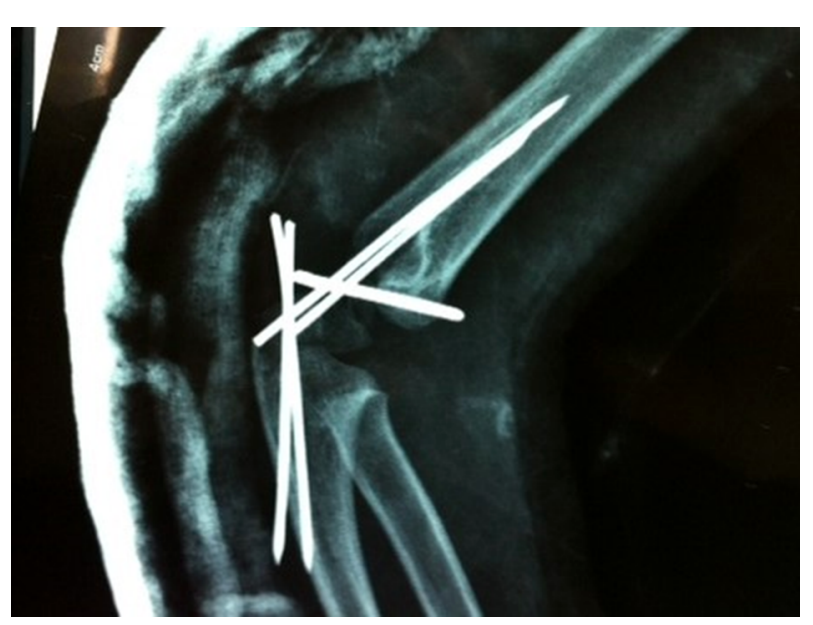

Figure 4. Immediate Postoperative X Ray Lateral View

\section{Discussion}

In view of the paucity of literature and rare incidence of such injuries, this case presentation highlights the presence of other injuries which can occur in association with LCM fractures in children. The importance of understanding the mode of complex trauma and the fracture pattern around the elbow joint is highlighted in the case report. 


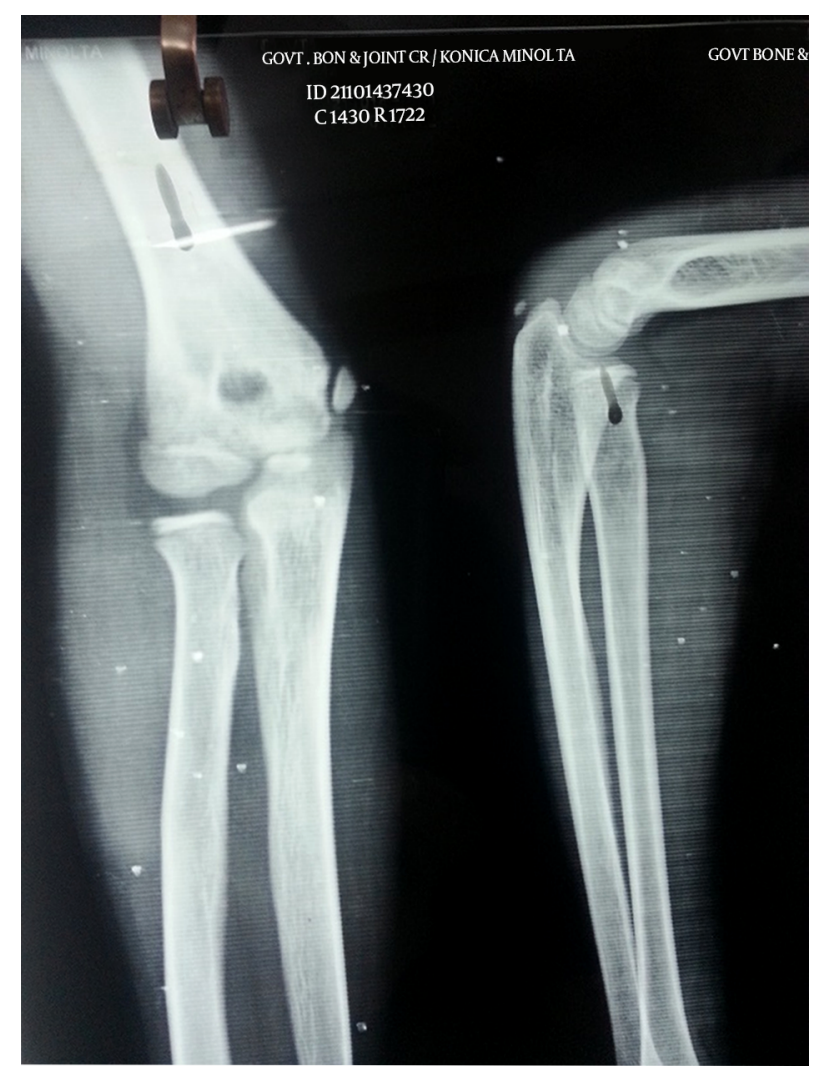

Figure 5. X Rays at 6 Months

LCM fractures usually occur between the ages of 5 to 10 years. The suggested mechanism of injury for LCMs are push-off and pull-off mechanisms (7). Herein, the authors think push-off of the lateral condyle by the radial head due to falling on an outstretched hand is a possible mechanism of injury in this patient as the forearm goes into valgus when extended. Fracture of the olecranon is due to the direct trauma to the elbow by the vehicle door due to deceleration of the vehicle. The two impacts of traumatic forces in one event is one thing which distinguishes this case from other reports mentioned in the literature. Even though this is a less common mechanism of olecranon injury, the authors maintain that this is the cause of the olecranon fracture in this patient (8). Displaced fractures of the lateral condyle need anatomical reduction and fixation since this is a Salter Harris type IV injury and inadequately reduced and treated fractures lead to nonunion, malunion, carrying angle abnormalities, and late onset neural palsy $(1,7,9,10)$. Metaphyseal olecranon fractures are due to a direct blow to the elbow. Graves and Canale (11) recommended that surgical intervention is to be limited to those patients with $>5 \mathrm{~mm}$ of displacement of the fracture ends.
The olecranon fracture in this case was displaced and so was managed by open reduction and internal fixation.

Wilkins (12) recommended assessing the stability of the olecranon fracture by direct palpation and flexion of the elbow joint. If either manoeuvre causes separation of the fragments, open reduction and internal fixation is required. Most of these cases of olecranon fractures have been diagnosed intraoperatively in other reported series. However, in this, report, the fracture was diagnosed preoperatively due to the displaced olecranon fracture.

Pace et al. published a case report of combined olecranon and LCM fractures in 2005 (2). Previous reports of concomitant LCM-olecranon fractures have been documented without further details by Gicquel et al. (13) (1 of 26), by Caterini et al. (14) (4 of 63), and by Gaddy et al. (15) (1 of 35).

Sharma et al. have found a significant difference in the ages of children with LCM injury and suggested that the olecranon is weaker in the younger child and fails next after the LCM. In older children, the ligaments, particularly the medial collateral, are probably the next weakest link after the LCM. They also suggested that an undisplaced LCM cohort with associated olecranon fracture can be treated nonoperatively, without assessment of stability, under general anesthesia. The present case was managed by internal fixation due to displaced fractures of the olecranon and lateral condyle. Displaced LCM-olecranon fractures should be managed by open reduction and internal fixation, as suggested by Sharma et al. (16).

This case illustrates that proper understanding of the normal anatomy of pediatric elbows and possible mechanisms of injury are of the utmost importance in understanding the different types of elbow injuries and their possible association with other injuries. This is the hallmark for early decision, management, and rehabilitation of such injuries in children.

\section{Footnote}

Authors' Contribution: Munir Farooq described the mechanism of injury and review of literature. Younis Kamal drafted the manuscript and compiled of the data, clinical photos, and x-rays. Hayat Ahmad Khan helped in the initial writing of the manuscript and literature review of the manuscript. Naseemul Gani helped in writing up of the discussion part of the manuscript. Adil Bashir Shah collected the references for the article. Mohammad Ashraf Khan helped in collecting the patient profile. Shahid Bhat helped writing the references of the manuscript. 

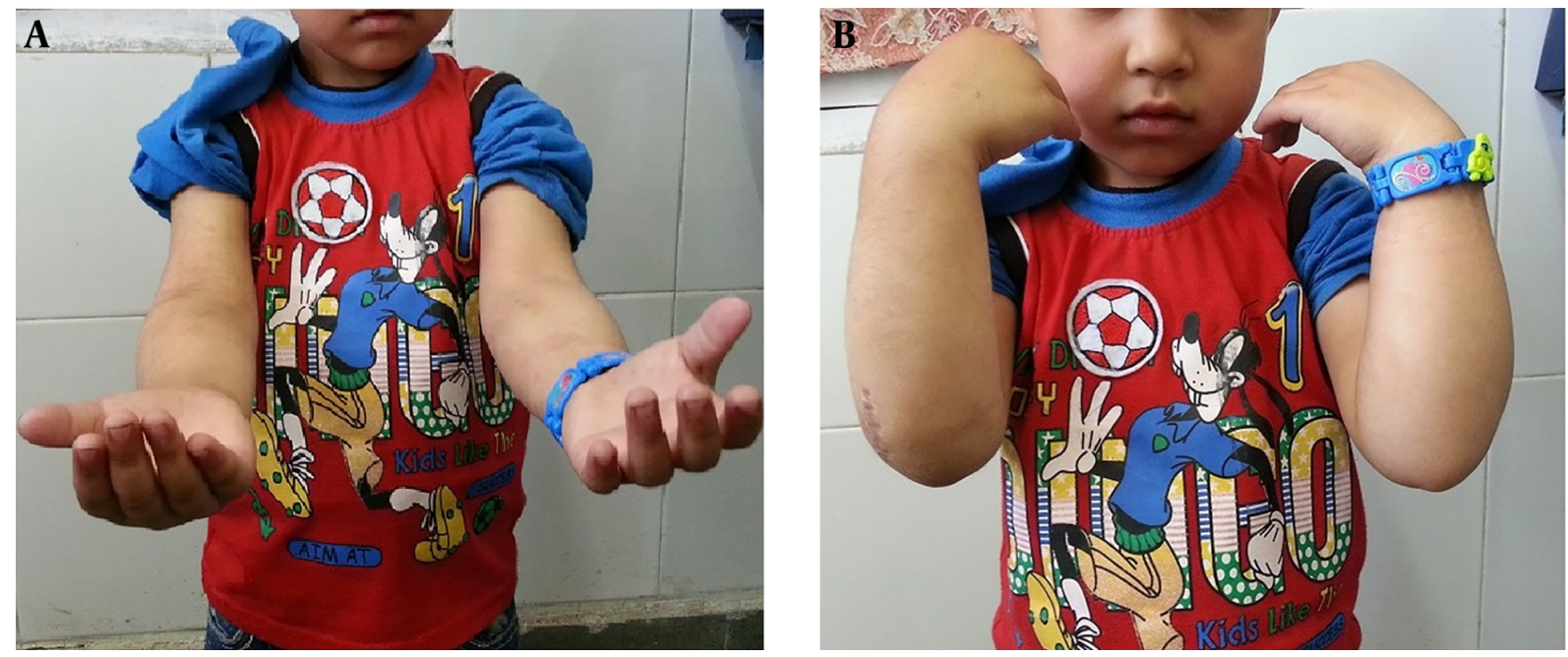

Figure 6. Showing Clinical ROM at 12 Weeks

\section{References}

1. Hardacre JA, Nahigian SH, Froimson AI, Brown JE. Fractures of the lateral condyle of the humerus in children. J Bone Joint Surg. 1971;53(6):1083-95.

2. Pace A, Gibson A, Al-Mousawi A, Matthews SJ. Distal humerus lateral condyle mass fracture and olecranon fracture in a 4-year-old female-review of literature. Injury Extra. 2005;36(9):368-72. doi: 10.1016/j.injury.2005.01.022.

3. Conner AN, Smith M. Displaced fractures of the lateral humeral condyle in children.J Bone Joint Surg Br Vol. 1970;52(3):460-4.

4. Foster DE, Sullivan JA, Gross RH. Lateral humeral condylar fractures in children.J Pediatr Orthop. 1985;5(1):16-22. [PubMed: 3884662].

5. Sharma H, Ayer R, Taylor GR. Complex pediatric elbow injury: an uncommon case. BMC Musculoskelet Disord. 2005;6:13. doi: 10.1186/14712474-6-13. [PubMed:15757518].

6. Thomas DP, Howard AW, Cole WG, Hedden DM. Three weeks of Kirschner wire fixation for displaced lateral condylar fractures of the humerus in children. J Pediatr Orthop. 2001;21(5):565-9. [PubMed: 11521019].

7. Jakob R, Fowles JV, Rang M, Kassab MT. Observations concerning fractures of the lateral humeral condyle in children.J Bone Joint Surg Br. 1975;57(4):430-6. [PubMed: 1104630].

8. Rockwood CA, Beaty JH, Kasser JR. Rockwood and Wilkins' fractures in children. Lippincott Williams \& Wilkins; 2010.
9. Ippolito E, Tudisco C, Farsetti P, Caterini R. Fracture of the humeral condyles in children: 49 cases evaluated after $18-45$ years. Acta Orthop Scand. 1996;67(2):173-8. [PubMed: 8623575].

10. Milch H. Fractures and Fracture Dislocations of the Humeral Condyles. JTrauma. 1964;4:592-607. [PubMed: 14208785].

11. Graves SC, Canale ST. Fractures of the olecranon in children: longterm follow-up. J Pediatr Orthop. 1993;13(2):239-41. [PubMed: 8459019].

12. Wilkins KE. In: Fractures in children. Rockwood CA, Wilkins KE, King R, editors. Philadelphia: Lippincott; 1991. pp. 509-828.Fractures and dislocations of the elbow region.

13. Gicquel PH, De Billy B, Karger CS, Clavert JM. Olecranon fractures in 26 children with mean follow-up of 59 months. J Pediatr Orthop. 2001;21(2):141-7. [PubMed: 11242238].

14. Caterini R, Farsetti P, D’Arrigo C, Ippolito E. Fractures of the olecranon in children. Long-term follow-up of 39 cases. J Pediatr Orthop B. 2002;11(4):320-8. [PubMed: 12370584].

15. Gaddy BC, Strecker WB, Schoenecker PL. Surgical treatment of displaced olecranon fractures in children.JPediatr Orthop. 1997;17(3):3214. [PubMed: 9150019].

16. Sharma H, Sibinski M, Sherlock DA. Outcome of lateral humeral condylar mass fractures in children associated with elbow dislocation or olecranon fracture. Int Orthop. 2009;33(2):509-14. doi: 10.1007/s00264-007-0463-1. [PubMed: 17940766]. 